\author{
People are often afraid of revealing their \\ inadequacies, especially in front of \\ colleagues they know.
}

\title{
OPINION
}

\section{Tell it how it is}

"Nothing against you personally...but I really hate dentists!" How many times have you heard those words (or words like them)? How many times have you held back the smart retort and just smiled gently or provided some reassuring comment to try and calm the patient? How stressful is it for all the dental team to continually cope with patients who tend to express their anxiety with inappropriate behaviour or language?

Studies suggest that somewhere between 20\% to 25\% of patients suffer from anxiety prior to a dental appointment. Obviously this means dealing with anxiety is a major part of every dental practice's day. One way of helping people do this is to provide training in communication skills, and the paper on page 101 in this issue describes an evaluation of the effectiveness of a skills training programme for the management of dental anxiety in The Netherlands. In my view the paper makes fascinating reading, not just for the findings but also for the ideas and thoughts it generates when you read it.

The main conclusions of the paper are that the training programme described in the paper is effective at helping dental students communicate with anxious patients, but moreso in the improvement of their behaviour rather than simply the acquisition of new knowledge. This improvement is in skills related to subjects such as using open questions, avoiding double questions, effective listening, avoiding technical language, paraphrasing and similar techniques. The researchers suggest this improvement may well be due to the practical elements of the training (role play) and the provision of a Learner Report, which was an opportunity for the students to give feedback on any insights gained during or after the training.

It is here, in the qualitative aspects of the Learner Report, that I suspect most of the really relevant learning took place. It is a brave person who is prepared to divulge insights gained following role-play, often because these insights are about deeply-held beliefs and prejudices that we may not even be aware of. I well remember discovering one of my own prejudices following some role-play and the experience was not pleasant as the prejudice made me behave (unknowingly) in a manner that I was ashamed of. But, once the pain of self-discovery had waned, I was able to recognise my prejudice and adjust my behaviour in future, which made me more effective in my job.

As the research paper shows, some of the insights gained by the students in The Netherlands may have been painful for them. For example one insight reported was;

'... I have learnt that it is not true that I draw correct conclusions from the information of the patient ...' This is a true insight, and one that will hopefully forge much better relationships between the dentist involved and his or her staff and patients, whether anxious or not.

Perhaps one of the difficulties for all of us when it comes to topics like this is the fear most people have for role-play. This is a very real fear, and a powerful one - so much so that it threatens to prevent a learning environment. People are often afraid of revealing their inadequacies, especially in front of colleagues they know. People are also afraid of 'looking foolish' or 'making a mistake'. This attitude is much stronger in skills-training than knowledge acquisition. After all, we are happier to admit not knowing the answer than demonstrating we cannot do it (whatever 'it' is). Hence, the older we get the less we like to reveal our inability to do something, as if somehow age confers additional skills. All of this acts as a deterrent for communication skills training, skills that will truly enhance our expertise in the eyes of both colleagues, staff and patients.

But I suspect there is often another reason why we shy away from communication skills training. I think people often believe that you have either got these skills - or you haven't. This research demonstrates that the belief about people being 'natural' communicators is only part of the story, and that everyone can improve their ability to communicate, in some cases substantially. Now that is a major change in thinking for some people, and one that is well worth acquiring.

$$
\begin{array}{r}
\text { Mike Grace, Editor } \\
\text { m.grace } @ \text { bda.org } \\
\text { doi:10.1038/sj.bdj.4810890 }
\end{array}
$$

